\title{
Turismo de Base Comunitária: uma reflexão sobre seus conceitos e práticas
}

Community Based Tourism: a discussion regarding its concepts and practices

Turismo de base comunitária: una discusión cerca de sus conceptos y práticas

http://dx.doi.org/10.18472/cvt.16n3.2016.1178

Nathalia Hallack Fabrino <nathalia.hallack@gmail.com >

Universidade de Brasília (UnB), Brasília, DF, Brasil.

Elimar Pinheiro do Nascimento 〈elimarcds@gmail.com >

Universidade de Brasília (UnB), Brasília, DF, Brasil.

Helena Araújo Costa < helenacosta@unb.br >

Universidade de Brasília (UnB), Brasília, DF, Brasil.

CRONOLOGIA DO PROCESSO EDITORIAL

Recebimento do artigo: 16-nov-2015

Aceite: 20 -jul-2016

FORMATO PARA CITAÇÃO DESTE ARTIGO

FABRINO, N. H.; NASCIMENTO, E. P. do; COSTA, H. A. Turismo de Base Comunitária: uma reflexão sobre seus conceitos e práticas. Caderno Virtual de Turismo. Rio de Janeiro, v. 16, n. 3, p. 172190, dez. 2016.

REALIZAÇÃO

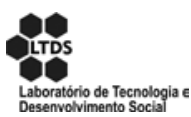

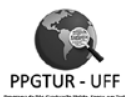

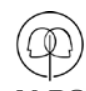

APOIO INSTITUCIONAL

EDIÇÃO

PATROCÍNIO

COPPE

UFR] 


\section{RESUMO}

O Turismo de Base Comunitária (TBC) traz uma proposta de desenvolvimento de turismo na escala local e centrado nos recursos endógenos das comunidades. A literatura ressalta seu potencial de promover a conservação ambiental, a valorização da identidade cultural e a geração de benefícios para as comunidades receptoras. Este artigo tem como objetivo verificar a aderência entre a discussão teórico-conceitual do TBC e as suas práticas. A revisão teórica do tema permitiu elaborar seis elementos-chaves (dominialidade, organização comunitária, democratização de oportunidades e repartição de benefícios, integração econômica, interculturalidade e qualidade ambiental), desdobrados em critérios e subcritérios. Este quadro de análise teórico foi aplicado empiricamente em três iniciativas da Rede Tucum no Ceará (Brasil): Ponta Grossa, Assentamento Coqueirinho e Prainha do Canto Verde. Concluiu-se que dos seis elementos-chaves inicialmente propostos, apenas dois devam ser considerados como aspectos constituintes do TBC na teoria e na prática: dominialidade e organização comunitária. Os outros quatro elementos foram identificados como possibilidades ou desdobramentos desejáveis do TBC.

Palavras-chave: Turismo de base comunitária (TBC). Rede Tucum. Turismo sustentável. Brasil.

\section{ABSTRACT}

The Community-based tourism (TBC) presents a tourism development proposal on a local scale and centered on the endogenous resources of the communities. The literature emphasizes its potential to promote environmental conservation, cultural identity and to enhance benefits to host communities. This work aims to analyze the adherence between the literature conceptual discussion about TBC and their actual practices. The theoretical framework led to the development of six key elements (dominion, community organization, democratization of opportunities and benefits sharing, economic integration, intercultural exchange and finally environmental quality), which were divided into criteria and sub-criteria. The analysis took place on three Initiatives linked to Tucum Network in Ceará (Brazil): Ponta Grossa, Settlement Coqueirinho and Prainha do Canto Verde. It was concluded that only two of the six key elements initially proposed should be considered as constituent aspects of TBC: dominion and Community Organization. The other four elements were identified as possibilities or aimed aspects of TBC.

Keywords: Community-based tourism (TBC). Tucum Network. Sustainable tourism. Brazil.

\section{RESUMEN}

El turismo de base comunitária (TBC) trae una propuesta de desarrollo turístico en el ámbito local, y centrado en recursos endógenos de las comunidades. La literatura destaca su potencial de promover conservación ambiental, la identidad cultural y mayorar beneficios en las comunidades de acogida. Este trabajo tiene como objetivo verificar la adherencia entre una discussion conceptual del TBC y sus prácticas. La revisión del tema teórico permitió el desarrollo de seis elementos claves (dominio, organización de la comunidad, democratización de oportunidades y beneficios, integración económica, interacción intercultural y calidad ambiental), desglosado en los criterios y subcriterios. Este marco de análisis se aplicó en trés experiéncias de la Red Tucum en Ceará, Brasil: Ponta Grossa, Coqueirinho y Prainha do Canto Verde. Se concluyó que dentre los seis elementos claves propuestos inicialmente, sólo dos se deben considerar como aspectos constitutivos de TBC: el dominio y la organización comunitaria. Los otros cuatro elementos fueron identificados como posibilidades o aspectos deseados del TBC.

Palabras clave: Turismo de base comunitária (TBC). Red Tucum. Turismo sostenible. Brasil.. 


\section{Introdução}

O turismo de base comunitária (TBC), ou turismo comunitário, consiste em um modelo de desenvolvimento turístico centrado nos recursos (humanos, naturais e de infraestrutura) endógenos de determinada localidade. Assim, carrega em sua essência o protagonismo das comunidades receptoras na gestão e oferta de bens e serviços turísticos (COSTA, 2013). Na literatura específica e programas oficiais de fomento, o TBC é apresentado como uma proposta fortemente associada ao turismo sustentável e ao desenvolvimento local (CORIOLANO, 2009; SANSOLO; BURSZTYN, 2009; IRVING, 2009).

A reflexão sobre o TBC no Brasil, durante muitos anos, trouxe consigo um sentido periférico, distante da realidade e das tendências políticas nacionais e internacionais. Nesse período, poucos profissionais mergulharam no campo de investigação do TBC. Tal realidade perdurou até meados da década de 1990, quando um movimento de pesquisadores de diferentes inserções do país levou essa discussão para o Encontro de Turismo de Base Local (ENTBL). O encontro demonstrou a demanda por fóruns dessa natureza e viabilizou a consolidação de redes não formais de pesquisas. $\mathrm{O}$ engajamento de pesquisadores em torno do TBC possibilitou o desenvolvimento de pesquisas, projetos e publicações sobre a temática. No entanto, esta produção acadêmica permaneceu nos "bastidores" até recentemente (IRVING, 2009).

Para Irving (2009), um novo olhar sob o TBC ocorre a partir da convergência de uma série de fatores surgidos em âmbito nacional e internacional, a saber: (i) a interpretação política do turismo como uma alternativa para a inclusão social; (ii) o fortalecimento de temas como a participação social e a governança democrática; (iii) a existência do capital social e o compromisso de "stakeholder engagement" como elementos fundamentais nas ações empreendidas por projetos internacionais; (iv) a inclusão do turismo nas pautas de ONGs de alcance internacional, associado a temáticas sociais e ambientais; (v) a mudança sutil no perfil dos turistas, agora mais comprometidos com a responsabilidade social e ambiental; (vi) a exigência de novas demandas na seara do planejamento, fruto da constatação de que o desenvolvimento do turismo, por vezes, não favorece as populações locais, contribuindo para a exclusão social; (vii) a emergência dos debates sobre o "turismo e sustentabilidade".

Embora o tema tenha alcançado maior visibilidade, autores como Blackstock (2005) consideram a literatura do TBC ingênua e irrealista. Fica evidenciado que essa produção acadêmica ainda carece de aprofundamentos e de debates mais criteriosos que aproximem seus fundamentos teóricos das iniciativas em curso.

Assim, este trabalho dedicou-se ao objetivo de verificar a aderência entre a discussão teórico-conceitual do TBC e as suas práticas, considerando como locus de pesquisa três iniciativas integrantes da Rede Tucum $^{1}$ no Ceará (Brasil). A partir desse objetivo, o artigo foi estruturado em quatro partes, além desta introdução. A primeira retrata, de forma sucinta, a revisão teórica do tema que permitiu embasar uma proposta de quadro referencial de análise de elementos-chaves, constitutivos do TBC, desdobrados em critérios e subcritérios que serviram para a verificação empírica. A segunda parte apresenta a metodologia do estudo e o campo de pesquisa; em seguida, na terceira, discutem-se os resultados encontrados nas experiências em relação aos elementos-chaves. Por fim, na quarta parte, as considerações finais apresentam o alcance e as adequações necessárias ao quadro de análise inicialmente proposto.

1 Rede Cearense de Turismo Comunitário. 


\section{Turismo de Base Comunitária (TBC) e seus elementos-chaves: uma proposta de quadro referencial para análise de iniciativas}

Embora não haja uma definição amplamente aceita do TBC, a literatura específica considera, como elemento comum, a interpretação da comunidade como sujeito de seu próprio avanço, participando da concepção, desenvolvimento e gestão do turismo (LTDS, 2011; CORIOLANO, 2003, 2009; SANSOLO; BURSZTYN, 2009; IRVING, 2009).

O MTur (BRASIL, 2010) traça como princípios comuns ao TBC: a autogestão; o associativismo e cooperativismo; a democratização de oportunidades e benefícios; a centralidade da colaboração, parceria e participação; a valorização da cultura local e, principalmente, o protagonismo das comunidades locais na gestão da atividade e/ou na oferta de bens e serviços turísticos, visando à apropriação por parte destas dos benefícios advindos do desenvolvimento da atividade turística.

Dixey $^{2}$, por sua vez, adotou a definição proposta por Mike Fabricius, para quem o TBC ocorre sempre que: (i) a comunidade local tem o uso e/ou direitos de propriedade dos recursos (tangíveis e intangíveis) utilizados para fins turísticos; (ii) a comunidade local, por meio de uma entidade (representante legal), desempenha um papel direto na tomada de decisão, direção e gestão dos recursos turísticos; (iii) o objetivo seja que a comunidade receba benefícios líquidos diretamente e/ou indiretamente de iniciativas de turismo.

Para Sansolo e Bursztyn (2009), a conservação ambiental, a valorização da identidade cultural e a geração de benefícios diretos para as comunidades receptoras são os componentes sustentadores desta proposta de turismo. Segundo esses autores, o turismo comunitário não representa apenas mais um segmento do mercado, e sim a possibilidade de um novo paradigma para o turismo. O potencial da atividade não se restringe aos benefícios econômicos, contribuindo também para o processo de revalorização da identidade cultural e para a manutenção do modo de vida das populações tradicionais ${ }^{3}$.

Contudo, o desenvolvimento do turismo comunitário (ou de base comunitária) só poderá ocorrer se os protagonistas dos destinos forem sujeitos e não objetos do processo, afirma Irving (2009). Na tentativa de delinear uma conceituação para o turismo comunitário, a autora apresenta algumas premissas que emergem como elementos centrais dessa atividade: (i) base endógena da iniciativa e desenvolvimento local; (ii) participação e protagonismo social no planejamento, implementação e avaliação de projetos turísticos; (iii) escala limitada e impactos sociais e ambientais controlados; (iv) geração de benefícios diretos à população local; (v) afirmação cultural e interculturalidade; (vi) compartilhamento e aprendizagem mútua entre o turista e os atores locais.

A geração de benefícios diretos para as comunidades receptoras representa um componente de destaque no TBC. Algumas definições, no entanto, vão além, defendendo que o turismo comunitário deve se comprometer a dividir os benefícios advindos do turismo entre os membros da comunidade (MALDONADO, 2009). Há ainda aqueles que associam o TBC às práticas da economia solidária, que tem como princípios a autogestão, a democracia, a participação, a cooperação e a distribuição igualitária (SINGER, 2010; SAMPAIO et al., 2009). Logo, espera-se que o TBC seja impulsionador do desenvolvimento local. Aspecto confirmado por Aref et al. (2010), para quem o turismo é visto como uma ferramenta-chave para

\footnotetext{
2 Conteúdo retirado da entrevista de Dixey, concedida ao Instituto Virtual de Turismo - IVT (sem data), disponível em <http://www. ivtrj.net/ivt/indice.aspx?pag=n\&id=11623\&cat=\%C2\%Ao\&ws=0〉. Mike Fabricius, consultor internacional desde 2004 , é um experiente gerente e empresário, que desempenhou um papel de liderança no desenvolvimento da indústria do turismo sul-africano.

3 As comunidades tradicionais, segundo Diegues (2004), estão relacionadas com uma forma de organização econômica e social baseada na reduzida acumulação de capital. Caracteriza-se por produtores independentes envolvidos em atividades econômicas de pequena escala, como a pesca, a agricultura, a coleta e o artesanato.
} 
o desenvolvimento comunitário. Os autores indicam que muitas comunidades se voltaram para o turismo em busca de desenvolvimento econômico, social, cultural e geral da localidade. No entanto, ressaltam que existe uma via de mão dupla, pois "o processo de desenvolvimento do turismo em uma comunidade é o processo de desenvolvimento comunitário em si” (2010, p. 157).

Lima (2002), entretanto, alerta haver um caráter potencial, e não automático, na relação entre o turismo e o desenvolvimento. Ao contrário de outras atividades econômicas que podem ser analisadas de uma perspectiva estritamente local - como é o caso da pesca, da agricultura de subsistência, da caça coletiva e de atividades voltadas para as necessidades de um pequeno grupo social em geral - o turismo tem a peculiaridade de ser um sistema local-global, que exige, ao mesmo tempo, um forte enraizamento local e um dinâmico enredamento global das atividades turísticas integradas às demais atividades e setores. $\mathrm{Ou}$ seja, o turismo sempre depende de um contexto externo para desenvolver-se "internamente". Dessa forma, duas questões são apontadas como sendo de grande relevância: a integração entre as escalas dos fenômenos (local, regional, nacional e global e vice-versa) e, de forma associada, a integração intersetorial das atividades econômicas e sociais (por exemplo: turismo, agroindústria, infraestrutura, educação, cultura, segurança, etc.).

A proposta de um desenvolvimento local alavancável por meio do turismo, para Benevides (1997), enseja a equalização de cinco objetivos, cuja compatibilização tende a ser problemática: preservação/conservação ambiental; identidade cultural; geração de ocupações produtivas e de renda; desenvolvimento participativo e qualidade de vida.

Dessa forma, fica evidente que a busca pelo desenvolvimento por meio do turismo comunitário impõe reflexões acerca dessas questões. Com base nos princípios, premissas, objetivos e componentes do TBC encontrados na literatura, delinearam-se como os elementos-chaves do turismo comunitário os seguintes aspectos:

- Dominialidade: refere-se ao grau de domínio da comunidade sobre os aspectos de controle, propriedade e gestão da atividade turística;

- Organização comunitária: diz respeito ao modelo e processo de gestão consolidado em torno do TBC, além de sua interação com o ambiente externo;

- Democratização de oportunidades e repartição de benefícios: refere-se à existência de mecanismos/acordos que contribuem para a repartição dos benefícios advindos da atividade turística na localidade e para a democratização de oportunidade no acesso de seus membros às atividades relacionadas ao turismo;

- Integração econômica: evidencia a integração do turismo com as outras atividades econômicas da localidade, identificando novos arranjos surgidos a partir do seu advento;

- Interculturalidade: relaciona-se com o intercâmbio cultural e a troca de referências e experiências estabelecidas entre os turistas e a comunidade local;

- Qualidade ambiental: refere-se às condições da comunidade com relação ao saneamento ambiental e, ainda, as formas de manejo dos recursos naturais locais.

Para cada elemento-chave foram atribuídos critérios correspondentes e o elemento "qualidade ambiental" recebeu, ainda, um grupo de subcritérios. Esses critérios e subcritérios foram definidos como parâmetros de análise, conforme apresentado no Quadro 1. 


\begin{tabular}{|c|c|c|c|c|c|c|c|c|c|c|c|c|c|}
\hline 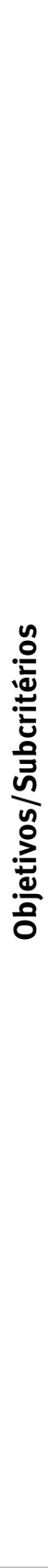 & 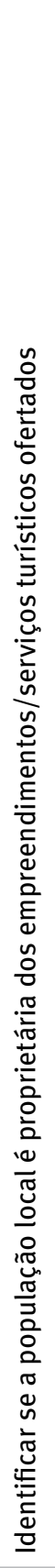 & 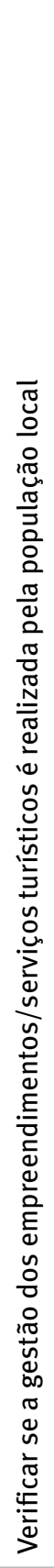 & 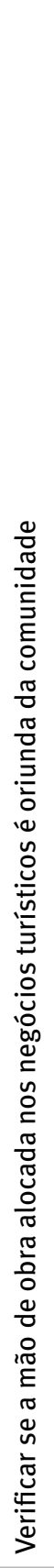 & 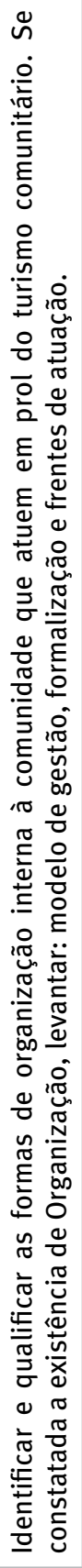 &  & 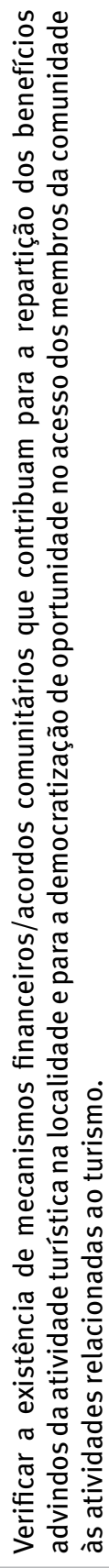 & & 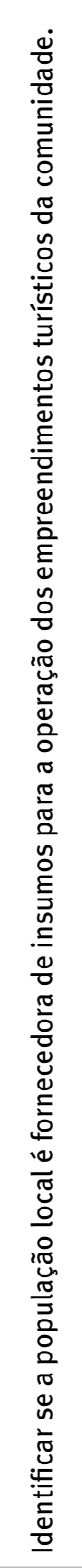 & 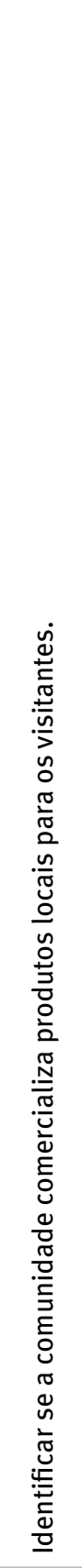 & 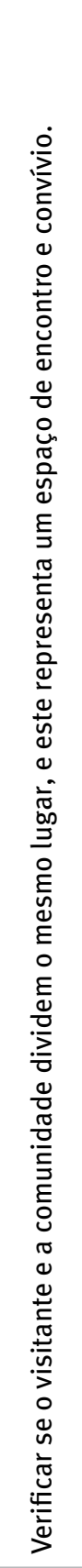 & 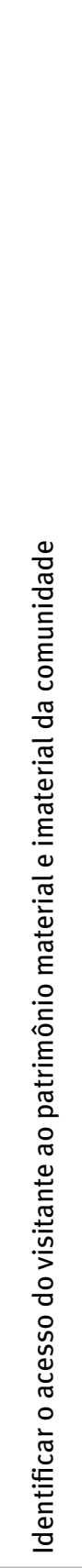 & 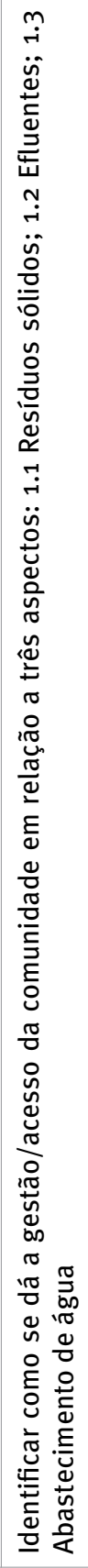 & 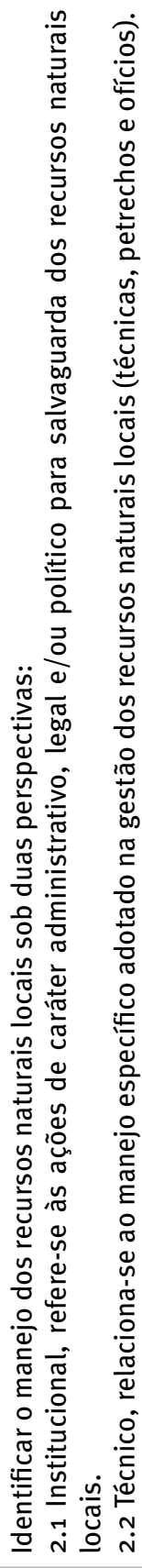 \\
\hline 兑 & 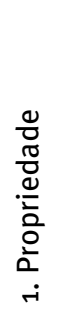 & 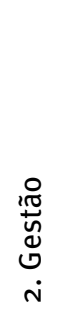 & 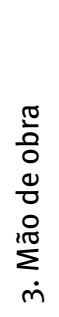 & 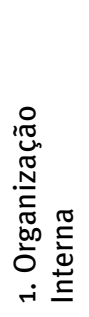 & 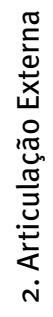 & 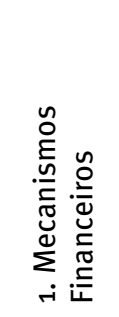 & 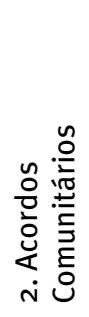 &  & 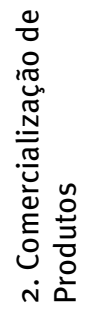 & 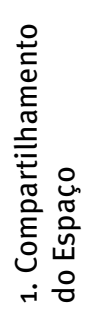 & 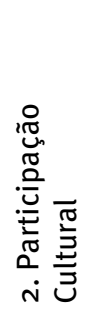 & 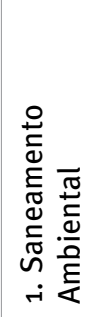 & 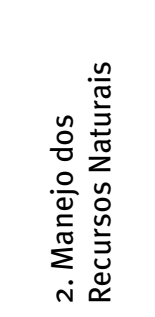 \\
\hline 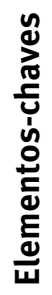 & \multicolumn{3}{|c|}{ 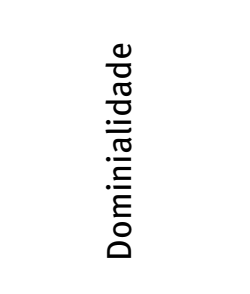 } & \multicolumn{2}{|c|}{ 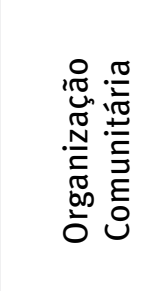 } & \multicolumn{2}{|c|}{ 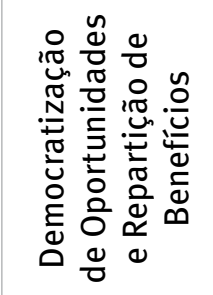 } & \multicolumn{2}{|c|}{  } & \multicolumn{2}{|c|}{ 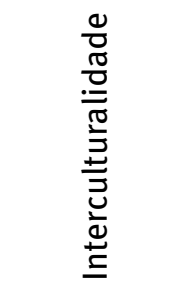 } & \multicolumn{2}{|c|}{ 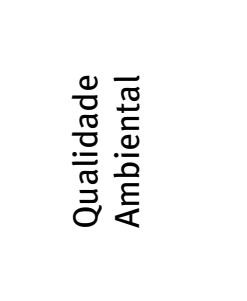 } \\
\hline
\end{tabular}




\section{Abordagem metodológica e campo de estudo}

A problemática definida exigiu, inicialmente, um trabalho de caráter analítico-descritivo, com abordagem essencialmente qualitativa, que foi desenvolvida em cinco etapas: i) pesquisa bibliográfica; ii) desenvolvimento do quadro de análise (elementos-chaves, critérios e subcritérios), com seleção das comunidades de estudo e elaboração dos questionários e formulários; iii) pesquisa de campo, envolvendo observação direta, pesquisa documental, diário de campo e aplicação dos questionários e dos formulários; iv) sistematização e análise das informações; v) confrontamento entre a revisão de literatura e os resultados obtidos em campo.

O quadro de análise apresentado na seção anterior foi aplicado para estudo de iniciativas integrantes da Rede Tucum. Lançada em maio de 2008, a Rede promove a articulação de comunidades que se propõem realizar o turismo de base comunitária (TBC) no Ceará. Das 13 iniciativas que compõem a Rede, três foram escolhidas para a pesquisa de campo deste estudo: Assentamento Coqueirinho, Ponta Grossa e Prainha do Canto Verde.

A Prainha do Canto Verde foi escolhida por sua notoriedade na prática de TBC. As outras duas comunidades por sua diversidade: Coqueirinho por ser um assentamento rural e Ponta Grossa por ser uma localidade de sucesso econômico. Assim, buscaram-se experiências que, embora estejam geograficamente próximas, possuem características peculiares, o que permite a análise do desenvolvimento do turismo comunitário em diferentes realidades e contextos.

O Assentamento Coqueirinho, localizado em Fortim, foi criado em 23 de agosto de 1995, ocupando uma área total de 1.473 hectares, dos quais 294,6 hectares são destinados à reserva legal. Logo após a sua criação, o Assentamento recebeu um total de 29 famílias, que foram instaladas em dois galpões e em 05 casas, já existentes no imóvel, além de barracas improvisadas pelos assentados. Atualmente, 63 famílias vivem no local, que conta com uma estrutura fundiária dividia em três agrovilas (sede, Agrovila II e Agrovila III). Por ser o único destino da Rede Tucum que não está localizado no litoral, ou seja, sem atrativos apoiados no modelo de sol e praia, o turismo no Assentamento relaciona-se ao dia a dia da vida rural.

A organização territorial do Assentamento, o modo de vida dos assentados e seus aspectos culturais constituem-se nos principais atrativos. A gestão da infraestrutura turística é realizada por um núcleo familiar, que lidera a Acoopac $c^{4}$, associação responsável pela captação de projetos para a melhoria da qualidade de vida dos moradores, com atuação direta sobre o turismo. A dinâmica do turismo baseia-se na convivência muito próxima do visitante com os assentados. A hospedagem e o restaurante estão integrados às residências. Os atrativos e as vivências têm a presença constante de membros da comunidade, que recebem e acompanham o turista durante toda a sua estada.

A Praia de Ponta Grossa abriga uma das comunidades litorâneas de Icapuí. A comunidade é um núcleo pesqueiro, caracterizado pela pesca da lagosta, formado por aproximadamente 214 pessoas (64 famílias). A maioria da população é descendente de holandeses e pertence a uma mesma família, de sobrenome Crispim. A paisagem do local, com cerca de $700 \mathrm{~m}$ de extensão, é composta por praias, dunas fixas e móveis e falésias coloridas.

4 Associação Cooperativista do Projeto de Assentamento Coqueirinho 
Em Ponta Grossa o turismo representa uma importante atividade econômica, mas é inexpressivo o número de turistas que visitam a comunidade pela sua proposta de turismo comunitário. A demanda turística local é formada, predominantemente, por turistas oriundos de Canoa Quebrada, que são atraídos pelas belezas naturais e pela tradição culinária local. Os três restaurantes locais - negócios privados, de propriedade de nativos e com capacidade de atendimento que varia entre 90 a 140 pessoas - representam o principal vetor do desenvolvimento turístico de Ponta Grossa. A partir da demanda turística nos restaurantes, a comunidade busca ampliar as possibilidades de ganhos, por meio da oferta de hospedagem, pontos de venda na praia e passeios na trilha ecológica e nas jangadas. No entanto, se comparado aos restaurantes, essas iniciativas ainda são pouco expressivas em retorno financeiro.

A Prainha do Canto Verde é uma comunidade pesqueira marítima que tem na pesca artesanal uma atividade de grande relevância socioeconômica e cultural. Localizada no distrito de Paripueira, situa-se em uma planície litorânea à beira-mar, em meio a campos de dunas (fixas e móveis), lagoas temporárias (interdunares) e planícies alagáveis. O início da ocupação na região se deu em 1860 e, hoje, a comunidade é formada por cerca de 1.100 habitantes, estabelecidos em uma área de 749 hectares com uma praia de 5 $\mathrm{km}$ de extensão.

Referência nacional no TBC, o turismo na Prainha do Canto Verde é explorado de forma sistemática desde 1997, ano de criação do Conselho de Turismo. A realidade encontrada, no entanto, revelou-se diferente das produções acadêmicas desenvolvidas, em sua maior parte, entre 2002 e $2004^{5}$. Atualmente, a localidade vivencia a polarização e os conflitos internos estabelecidos em função do decreto da Resex ${ }^{6}$, que enfraqueceu a coesão e a atuação do grupo comunitário e, consequentemente, da proposta de TBC.

\section{Apresentação e discussão de resultados}

A partir do quadro de análise conceitual construído neste trabalho, as iniciativas foram observadas, dando origem aos resultados aqui apresentados. A seção está estruturada ao redor dos seis elementos-chaves, sendo que cada tópico apresenta um quadro que sistematiza as observações empíricas, seguido por uma discussão comparativa entre as iniciativas.

\section{Dominialidade}

Dominialidade refere-se ao grau de domínio da comunidade sobre três dimensões: propriedade, gestão e mão de obra. O objetivo foi analisar: (i) se os nativos são proprietários dos empreendimentos e serviços turísticos ofertados; (ii) se a gestão do empreendimento é realizada por membros da comunidade; (iii) se a mão de obra é oriunda da comunidade.

5 Almeida (2002), Bursztyn et al. (2003), Lima (2002) e Mendonça (2004)

6 Em 05 de junho de 2009. 
Quadro 2 - Síntese dos resultados - Dominialidade.

\begin{tabular}{|c|c|c|c|}
\hline \multirow{2}{*}{ Critério } & \multicolumn{3}{|c|}{ Comunidades } \\
\hline & Ponta Grossa & Assentamento Coqueirinho & Prainha do Canto Verde \\
\hline Propriedade & $\begin{array}{l}\text { - População local } \\
\text { - Todos estão associados } \\
\text { à Astumac e vinculados à } \\
\text { proposta do TBC. }\end{array}$ & $\begin{array}{l}\text { - População local } \\
\text { - Todos estão associados } \\
\text { à Acoopac e vinculados à } \\
\text { proposta do TBC }\end{array}$ & $\begin{array}{l}\text { - População local: parte } \\
\text { dos empreendimentos } \\
\text { turísticos está associada } \\
\text { ao Conselho de Turismo } \\
\text { e vinculado à proposta } \\
\text { do TBC. Outros atuam } \\
\text { independentes da proposta } \\
\text { do turismo comunitário. } \\
\text { - Histórico de imóveis } \\
\text { vendidos para pessoas de } \\
\text { fora da comunidade. }\end{array}$ \\
\hline Gestão & - População local & - População local & - População local \\
\hline Mão de obra & - População local & - População local & - População local \\
\hline
\end{tabular}

Fonte: Elaborado pelos autores

De acordo com a literatura, o TBC tem como princípio norteador o controle efetivo da população local sobre as atividades econômicas associadas ao turismo. As realidades verificadas em Ponta Grossa e no Assentamento Coqueirinho convergem com este princípio: todos os empreendimentos e serviços existentes são de propriedade e gerenciados por nativos, assim como todos os empregos gerados são destinados aos membros da comunidade. Tal realidade é corroborada pelos entrevistados, pois muitos expuseram a importância da atividade turística ser desenvolvida apenas por nativos, combatendo qualquer possibilidade de participação, e ganho, de agentes externos.

A Prainha do Canto Verde apresentou um cenário mais diversificado: moradores envolvidos com a atividade turística, associados ao Conselho de Turismo e vinculados à proposta de turismo comunitário; moradores envolvidos com a atividade turística, integrantes da Associação Independente dos Moradores da Prainha do Canto Verde e desvinculados do turismo comunitário e, ainda, um número pequeno de imóveis vendidos para pessoas de fora da comunidade.

\section{Organização comunitária}

A organização comunitária subdivide-se em dois critérios: (i) organização interna e (ii) articulação externa. O primeiro critério almeja identificar a existência de alguma forma de organização interna que atue em prol do turismo comunitário. Constatada a existência de organização, segue-se para a qualificação de sua forma de gestão, formalização e frentes de atuação. Em um segundo momento, objetivou-se analisar como essas iniciativas se articulam externamente, verificando a existência de apoio financeiro e técnico voltados para o desenvolvimento do turismo comunitário. 
Quadro 3-Síntese dos resultados - Organização Comunitária

\begin{tabular}{|c|c|c|c|c|}
\hline \multirow[b]{2}{*}{ Critério } & \multirow[b]{2}{*}{ Subcritério } & \multicolumn{3}{|c|}{ Comunidades } \\
\hline & & Ponta Grossa & Assentamento Coqueirinho & $\begin{array}{c}\text { Prainha do Canto } \\
\text { Verde }\end{array}$ \\
\hline \multirow[t]{2}{*}{$\begin{array}{l}\text { Organização } \\
\text { Interna }\end{array}$} & $\begin{array}{l}\text { Presença de } \\
\text { Organização }\end{array}$ & $\begin{array}{l}\text { Associação de } \\
\text { Turismo, Meio } \\
\text { Ambiente e Cultura } \\
\text { - Astumac }\end{array}$ & $\begin{array}{l}\text { Associação Cooperativista } \\
\text { do Projeto de } \\
\text { Assentamento Coqueirinho } \\
\text { - Acoopac }\end{array}$ & $\begin{array}{l}\text { Conselho de Turismo } \\
\text { - Associação de } \\
\text { Moradores da } \\
\text { Prainha do Canto } \\
\text { Verde }\end{array}$ \\
\hline & $\begin{array}{l}\text { Formalização } \\
\text { da Organização }\end{array}$ & CNPJ ativo/regular & CNPJ ativo/regular & CNPJ ativo/regular \\
\hline $\begin{array}{l}\text { Articulação } \\
\text { externa }\end{array}$ & $\begin{array}{l}\text { Apoio } \\
\text { financeiro e } \\
\text { técnico }\end{array}$ & $\begin{array}{l}\text { - Rede Tucum } \\
\text { - Fundação Brasil } \\
\text { Cidadão } \\
\text { - Instituto Terramar } \\
\text { - Fundação Amigos } \\
\text { da Prainha do } \\
\text { Canto Verde }\end{array}$ & $\begin{array}{l}\text { - Rede Tucum } \\
\text { - Tremembê Onlus } \\
\text { - Cáritas Diocesana } \\
\text { Limoeiro do Norte } \\
\text { - Associação Caiçara de } \\
\text { Promoção Humana } \\
\text { - Fundação Amigos da } \\
\text { Prainha do Canto Verde }\end{array}$ & $\begin{array}{l}\text { - Rede Tucum } \\
\text { - Instituto Terramar } \\
\text { - Fundação Amigos } \\
\text { da Prainha do Canto } \\
\text { Verde }\end{array}$ \\
\hline
\end{tabular}

Fonte: Elaborado pelos autores

Os resultados de campo das três iniciativas evidenciaram os seguintes aspectos:

(i) Presença de Organizações com o modelo de gestão baseado no associativismo. Estas estão formalizadas (CNPJ ativo e regular) e com mecanismos de gestão (estatutos, regimento interno, atas, etc.) instituídos;

(ii) A centralidade da Associação com relação à atividade turística no território pode variar. No caso do Assentamento Coqueirinho, a Acoopac representa o principal vetor para o desenvolvimento do turismo. Em Ponta Grossa, o desenvolvimento turístico independe da atuação da organização local. Nesse caso, a Associação concentra-se na organização de uma demanda já existente e na ampliação das oportunidades de ganhos para a comunidade;

(iii) As associações possuem aporte externo (técnico e financeiro) de diferentes atores/instituições. Não obstante, conforme apontado na literatura, as $\mathrm{ONGs}^{7}$ representam as maiores incentivadoras da proposta de turismo comunitário;

(iv) As ações desenvolvidas por agentes externos focam não apenas no turismo, mas em uma melhoria ampla da qualidade de vida das comunidades. Aqui, também se percebe uma convergência entre a literatura e as iniciativas analisadas no que se refere à relação do TBC com as outras dimensões da vida comunitária, integrando um processo voltado para o desenvolvimento da comunidade como um todo.

7 Organizações não Governamentais. 


\section{Democratização de oportunidades e repartição de benefícios}

Este elemento-chave buscou identificar a existência de (i) mecanismos financeiros e (ii) acordos comunitários que contribuem para a repartição dos benefícios advindos do turismo e para a democratização no acesso da população às oportunidades geradas por essa atividade

$$
\begin{gathered}
\text { Quadro } 4 \text { - Síntese dos resultados - Democratização de Oportunidades e Repartição de } \\
\text { Benefícios. }
\end{gathered}
$$

\begin{tabular}{|l|l|l|l|}
\hline \multirow{2}{*}{ Critério } & \multicolumn{1}{|c|}{ Comunidades } \\
\cline { 2 - 4 } & \multicolumn{1}{|c|}{ Ponta Grossa } & Assentamento Coqueirinho & \multicolumn{1}{|c|}{$\begin{array}{l}\text { Prainha do Canto } \\
\text { Verde }\end{array}$} \\
\hline $\begin{array}{l}\text { Mecanismos } \\
\text { Financeiros }\end{array}$ & $\begin{array}{l}\text { - Fundo de Reserva/Fundo } \\
\text { Rotativo (não instituído) }\end{array}$ & $\begin{array}{l}\text { - Fundo de Reserva/Fundo } \\
\text { Rotativo (não instituído) }\end{array}$ & $\begin{array}{l}\text { Fundo Rotativo } \\
\text { - Fundo Social (sem } \\
\text { atuação nos últimos } \\
\text { anos) }\end{array}$ \\
\hline $\begin{array}{l}\text { Acordos } \\
\text { Comunitários }\end{array}$ & $\begin{array}{l}\text { - 1 negócio por pessoa } \\
\text { - As pousadas não oferecem } \\
\text { café da manhã. O café é } \\
\text { ofertado por lanchonetes } \\
\text { locais. }\end{array}$ & $\begin{array}{l}\text { - Não há acordos } \\
\text { comunitários formalizados, } \\
\text { mas há uma dinâmica de } \\
\text { solidariedade estabelecida } \\
\text { entre o grupo envolvido com a } \\
\text { atividade turística. }\end{array}$ & $\begin{array}{l}\text { - Sistema de } \\
\text { Rotatividade } \\
\text { (Indícios que não na rigidez no } \\
\text { rodízio) }\end{array}$ \\
\hline
\end{tabular}

Fonte: Elaborado pelos autores

Embora a verificação de campo tenha apontado a existência de mecanismos financeiros e acordos comunitários empreendidos pelas organizações locais, percebe-se que a operacionalização de tais iniciativas ainda representa um desafio. A coordenadora do turismo da Acoopac, no Assentamento Coqueirinho, por exemplo, sinalizou que os ganhos advindos do restaurante e dos chalés ainda são poucos e a maior parte é destinada para a melhoria dos próprios negócios, o que compromete o repasse de recursos ao Fundo Rotativo.

O fortalecimento desses mecanismos e acordos depende dos fluxos financeiros dos empreendimentos turísticos. Somente a partir de um retorno financeiro sustentado é que os proprietários poderão assumir e honrar os compromissos e acordos com as suas respectivas Associações e comunidade. Enquanto estiverem ocupados com o atendimento de necessidades básicas, será difícil destinar parte de um ganho, já limitado, para outros fins.

\section{Integração econômica}

O elemento-chave integração econômica visa evidenciar a relação do turismo com as outras atividades econômicas da localidade e foi analisado a partir de dois critérios: (i) se a população local é fornecedora de insumos para a operação dos empreendimentos turísticos e (ii) se a comunidade comercializa produtos locais para os visitantes. 


\section{Quadro 5 - Síntese dos resultados - Integração Econômica}

\begin{tabular}{|c|c|c|c|}
\hline \multirow[b]{2}{*}{ Critério } & \multicolumn{3}{|c|}{ Comunidades } \\
\hline & Ponta Grossa & $\begin{array}{c}\text { Assentamento } \\
\text { Coqueirinho }\end{array}$ & Prainha do Canto Verde \\
\hline $\begin{array}{l}\text { Fornecimento } \\
\text { de insumos/ } \\
\text { operação dos } \\
\text { empreendimentos } \\
\text { turísticos }\end{array}$ & $\begin{array}{l}\text { - Aquisição do } \\
\text { pescado por meio } \\
\text { de atravessadores. } \\
\text { - Oferta restrita de } \\
\text { produtos locais. }\end{array}$ & $\begin{array}{l}\text { - O restaurante só } \\
\text { compra nas comunidades } \\
\text { vizinhas os insumos que } \\
\text { não são produzidos no } \\
\text { Assentamento. }\end{array}$ & $\begin{array}{l}\text { - Produção de frutas e verduras } \\
\text { nas próprias pousadas. } \\
\text { - Preferência na aquisição de } \\
\text { insumos e produtos na própria } \\
\text { localidade. } \\
\text { - Aquisição do pescado direto } \\
\text { com os pescadores (caso do } \\
\text { Restaurante Sol e Mar). }\end{array}$ \\
\hline $\begin{array}{l}\text { Comercialização } \\
\text { de produtos/ } \\
\text { turista }\end{array}$ & - Inexpressivo & $\begin{array}{l}\text { - Cosméticos naturais, } \\
\text { artesanato de biscuit e } \\
\text { produtos provenientes da } \\
\text { agricultura familiar. }\end{array}$ & $\begin{array}{l}\text { - Grupos de artesanatos locais. } \\
\text { - Ponto de comercialização } \\
\text { de artesanato na Pousada e } \\
\text { Restaurante Sol e Mar. } \\
\text { - Ponto de comercialização } \\
\text { da Bodega (espaço de } \\
\text { comercialização de produtos da } \\
\text { região). }\end{array}$ \\
\hline
\end{tabular}

Fonte: Elaborado pelos autores

Os empreendimentos analisados privilegiam a aquisição de insumos e produtos para a operação de seus negócios na própria comunidade. Os proprietários compram as mercadorias diretamente dos moradores ou no comércio local. A opção de adquirir produtos locais apresenta-se mais vantajosa, pois poupa tempo e custos de deslocamento. Não obstante, a restrita disponibilidade de insumos e produtos na comunidade obriga alguns empreendimentos a buscarem mercadorias em outros locais.

Com relação à comercialização de produtos locais para o visitante, embora a Prainha do Canto Verde e o Assentamento Coqueirinho ofereçam algumas mercadorias, essa oferta ainda é restrita, inconstante e está condicionada à pouca disponibilidade de recursos financeiros dos envolvidos em investirem nos seus negócios. Esse cenário converge com alguns pontos levantados por Lima (2002) em seu trabalho sobre a Prainha do Canto Verde. Embora a autora tenha apontado uma diversificação na produção de artesanato (artesanato de madeira, de quenga de coco, pintura em tecidos e estamparia), também registrou algumas dificuldades: os cursos de profissionalização de pequena duração, realizados por entidades não governamentais, não criam a tradição do fazer - "não é porque uma pessoa fez um curso de pintura que estará, necessariamente, habilitada para pintar produtos vendáveis” (2002, p. 134); falta articulação entre os grupos de produção locais; o marketing é insuficiente, e falta capital de giro para sustentar a comercialização.

\section{Interculturalidade}

A Interculturalidade teve como intenção averiguar o intercâmbio cultural promovido pelas experiências de TBC, a partir da troca de referências e experiências entre os visitantes e a comunidade local. Esse elemento-chave foi analisado por meio de dois critérios: (i) o compartilhamento do espaço, que almejou verificar se o visitante e a comunidade dividem o mesmo lugar, e se este representa um espaço de encontro e convívio; (ii) a participação cultural, que objetivou identificar o acesso do visitante ao patrimônio cultural material e imaterial das comunidades. 
Quadro 6 - Síntese dos resultados - Interculturalidade

\begin{tabular}{|l|l|l|l|}
\hline \multirow{2}{*}{ Critério } & \multicolumn{1}{|c|}{ Comunidades } \\
\cline { 2 - 4 } & \multicolumn{1}{|c|}{ Ponta Grossa } & \multicolumn{1}{c|}{$\begin{array}{c}\text { Assentamento } \\
\text { Coqueirinho }\end{array}$} & \multicolumn{1}{c|}{ Prainha do Canto Verde } \\
\hline \multirow{2}{*}{$\begin{array}{l}\text { Compartilhamento } \\
\text { do espaço }\end{array}$} & $\begin{array}{l}\text { - Visitante e } \\
\text { comunidade } \\
\text { compartilham o } \\
\text { mesmo espaço. }\end{array}$ & $\begin{array}{l}\text { - Visitante e comunidade } \\
\text { compartilham o mesmo } \\
\text { espaço. }\end{array}$ & $\begin{array}{l}\text { - Visitante e comunidade } \\
\text { compartilham o mesmo espaço. }\end{array}$ \\
\hline Participação \\
cultural & $\begin{array}{l}\text { - Acesso irrestrito } \\
\text { do turista ao } \\
\text { patrimônio cultural } \\
\text { material e imaterial } \\
\text { da comunidade. }\end{array}$ & $\begin{array}{l}\text { turista ao patrimônio } \\
\text { cultural material e } \\
\text { imaterial da comunidade. }\end{array}$ & $\begin{array}{l}\text { - Acesso irrestrito do } \\
\text { patrimônio cultural material e } \\
\text { imaterial da comunidade. }\end{array}$ \\
\hline
\end{tabular}

Fonte: Elaborado pelos autores

As evidências desse elemento-chave foram bastante semelhantes entre as três comunidades de estudo. A conformação das iniciativas de TBC oferece um ambiente propício para a interação entre o visitante e a comunidade receptora. Destaque para o Assentamento Coqueirinho, onde esse ambiente conforma-se de maneira mais orgânica aos modos de vida locais, permitindo, assim, mais intensidade na interação turista-comunitário. Logo, no turismo comunitário não existe uma paisagem construída para o turismo, o visitante se integra a uma paisagem social preexistente que independe de sua presença. Conforme apontado por Irving (2009), as práticas de TBC representam um lócus de encontro, que promove, ao mesmo tempo, a afirmação das identidades do destino e o compartilhamento de múltiplas identidades, que se expressam e são intercambiadas.

\section{Qualidade ambiental}

A qualidade ambiental foi analisada a partir de dois critérios: (i) saneamento ambiental, subdividido em (a) gestão de resíduos sólidos, (b) gestão de efluentes e (c) abastecimento de água e (ii) manejo dos recursos naturais, subdividido em (a) institucional, referente às ações de caráter administrativo, legal e/ ou político para salvaguarda dos recursos naturais da comunidade; e (b) técnico, relacionado ao manejo específico dos recursos naturais locais - técnicas, petrechos e ofícios. 
Quadro 7 - Síntese dos resultados - Saneamento Ambiental

\begin{tabular}{|c|c|c|c|c|}
\hline \multirow[b]{2}{*}{ Critério } & \multirow[b]{2}{*}{ Subcritério } & \multicolumn{3}{|c|}{ Comunidades } \\
\hline & & Ponta Grossa & Assentamento Coqueirinho & $\begin{array}{c}\text { Prainha do Canto } \\
\text { Verde }\end{array}$ \\
\hline \multirow{3}{*}{$\begin{array}{l}\text { Saneamento } \\
\text { Ambiental }\end{array}$} & $\begin{array}{l}\text { Resíduos } \\
\text { Sólidos }\end{array}$ & $\begin{array}{l}\text { - Coleta Pública } \\
\text { - Lixo orgânico para } \\
\text { criações }\end{array}$ & $\begin{array}{l}\text { - Lixo seco enterrado/ } \\
\text { queimado; } \\
\text { - Lixo orgânico para } \\
\text { criações/compostagem }\end{array}$ & $\begin{array}{l}\text { - Coleta Pública } \\
\text { (insuficiente) } \\
\text { - Lixo orgânico } \\
\text { para criações/ } \\
\text { compostagem } \\
\text { (menor prevalência) }\end{array}$ \\
\hline & Efluentes & - Fossa biosséptica & - Fossa séptica & - Fossa séptica \\
\hline & $\begin{array}{l}\text { Abastecimento } \\
\text { de Água }\end{array}$ & $\begin{array}{l}\text { - Fornecimento } \\
\text { público } \\
\text { - Cisternas de } \\
\text { ferrocimento } \\
\text { - Ponto público de } \\
\text { água potável }\end{array}$ & - Poços artesianos & - Poços artesianos \\
\hline
\end{tabular}

Nos três critérios avaliados a comunidade de Ponta Grossa apresentou os melhores resultados, sendo também o local com o maior apoio externo no financiamento de ações relativas ao saneamento ambiental. A comunidade conta com aporte do município para a coleta de lixo e fornecimento de água, além de ter sido contemplada por um projeto do terceiro setor (Fundação Brasil Cidadão) que, com recursos privados (Petrobras Ambiental), implementou alternativas mais sustentáveis para a gestão de efluentes e captação de água.

No Assentamento Coqueirinho, o aporte externo é inexistente e na Prainha do Canto Verde é insuficiente. Embora essas iniciativas sejam "exemplos" de comunidades que buscam o desenvolvimento por meio de ações sustentáveis, há evidências de práticas degradadoras subjacentes às atividades diárias das comunidades, a exemplo da disposição inadequada dos resíduos - fator comprometedor do meio ambiente e da saúde pública. 
Quadro 8 - Síntese dos resultados - Manejo dos Recursos Naturais

\begin{tabular}{|c|c|c|c|c|}
\hline \multirow[b]{2}{*}{ Critério } & \multirow[b]{2}{*}{ Subcritério } & \multicolumn{3}{|c|}{ Comunidades } \\
\hline & & Ponta Grossa & Assentamento Coqueirinho & $\begin{array}{c}\text { Prainha do Canto } \\
\text { Verde }\end{array}$ \\
\hline \multirow{2}{*}{$\begin{array}{l}\text { Manejo dos } \\
\text { recursos } \\
\text { naturais }\end{array}$} & Institucional & $\begin{array}{l}\text { - Criação da APA. } \\
\text { - Respeito ao } \\
\text { defeso da lagosta } \\
\text { (lei federal). }\end{array}$ & $\begin{array}{l}\text { - Áreas destinadas a APP e } \\
\text { Reserva Legal. } \\
\text { - Acordos internos. } \\
\text { - Conflitos internos } \\
\text { (divergências entre as } \\
\text { Associações). }\end{array}$ & $\begin{array}{l}\text { - Criação da Resex. } \\
\text { - Acordos internos. } \\
\text { - Militância. } \\
\text { - Conflito interno } \\
\text { (Resex Terrestre). }\end{array}$ \\
\hline & Técnico & $\begin{array}{l}\text { - Pesca artesanal. } \\
\text { - Projeto } \\
\text { "Minifazenda } \\
\text { Marinha" (extinto). }\end{array}$ & $\begin{array}{l}\text { - Produção orgânica e } \\
\text { manejo integrado de } \\
\text { recursos. }\end{array}$ & - Pesca artesanal. \\
\hline
\end{tabular}

Fonte: Elaborado pelos autores

As comunidades de Ponta Grossa e da Prainha do Canto Verde vislumbraram, na transformação de seus territórios em Unidades de Conservação (UC), estratégias para a conservação dos recursos naturais locais e coerção da especulação imobiliária. Essas localidades têm na pesca artesanal uma das principais fontes de renda. Segundo Almeida e Pinheiro (2004), a pesca artesanal representa uma atividade que carrega alguns elementos da sustentabilidade, a saber: uso predominante de recursos naturais renováveis (inclusive com propulsão eólica ou a remo); captura de uma grande diversidade de espécies, incidindo sobre diferentes elos da teia alimentar marinha; reduzido impacto ambiental (baixo poder de captura); conhecimento aprofundado sobre o meio ambiente, recursos e limites naturais, e orientação da pescaria de acordo com condições ambientais e de abundância de espécies.

O Assentamento Coqueirinho, por sua vez, apresenta um cenário polarizado entre aqueles que estão envolvidos com o turismo comunitário e comprometidos com acordos e práticas que promovam o bem-estar coletivo e a conservação dos recursos naturais e produtivos, e os membros das outras Associações, que priorizam sistemas de produção individuais com tendências ao esgotamento dos recursos locais.

\section{Considerações finais}

O objetivo deste artigo foi verificar a aderência entre a discussão conceitual do TBC e as suas práticas, a partir da elaboração e aplicação de um quadro referencial de análise em três experiências ligadas à Rede Tucum. Com a revisão teórica, foi possível levantar seis elementos-chaves (dominialidade, organização comunitária, democratização de oportunidades e repartição de benefícios, integração econômica, interculturalidade e qualidade ambiental), subdivididos em critérios e subcritérios. A aplicação desse quadro nas iniciativas de turismo comunitário selecionadas possibilitou a verificação da efetividade de cada um e, por conseguinte, a sua real relevância como um aspecto constituinte para o TBC. Desse encontro entre a teoria e a prática foi possível concluir que: 
A Dominialidade se destaca como a principal característica do TBC, e se faz presente nos locais estudados. O trabalho de campo evidenciou, no entanto, que apenas uma parcela dos membros das comunidades visitadas está envolvida nas atividades relacionadas ao turismo. Ressalta-se que a literatura associa o TBC a uma proposta de desenvolvimento turístico que envolve a comunidade como um todo.

Este é um ponto importante: o turismo de base comunitária não necessariamente envolve toda a comunidade, mas grupos, eventualmente pequenos, de moradores. O controle efetivo das atividades relacionadas ao turismo pela comunidade local é uma condição sine qua non dessa proposta. Logo, sem a dominialidade não há turismo de base comunitária. É esse elemento-chave que garante o estabelecimento dos direitos de propriedade ${ }^{8}$ nas diversas dimensões da atividade. Também é dele que decorre a criação de uma reserva de mercado em favor da comunidade e o desenvolvimento de uma cadeia produtiva do turismo.

A Organização Comunitária também representa um elemento constitutivo do turismo comunitário. Não há um modelo predeterminado para essa organização (forma e gestão), mas ela deve estar presente como uma representação legal dentro da própria comunidade e na sua interação com o ambiente externo. Não obstante, é necessário aprofundar as pesquisas sobre esse elemento, buscando um melhor entendimento da influência e importância dessas organizações para os seus membros, para a comunidade como um todo e, principalmente, o seu impacto no desenvolvimento turístico local.

Acredita-se que a forma de atuação dessas organizações esteja menos relacionada a modelos de gestão coletiva e cooperativa, e mais próxima de um mecanismo regulatório cuja finalidade é organizar, regular e/ou fiscalizar a atividade turística no território, por meio da instituição de diretrizes e normas de convivência e operação da atividade turística. Caberão a essas organizações o estabelecimento de acordos comunitários e instituições sociais que ampliem as oportunidades de inserção e fixação de membros da comunidade na atividade turística.

Segundo a literatura, o TBC surge em contextos em que as comunidades já estão mobilizadas em outras frentes de resistência ou de agregação, como a luta pela posse da terra, pela conservação dos recursos naturais, pelo direito à educação e saúde, etc. O presente trabalho corrobora esse entendimento, considerando que as três comunidades estudadas possuem um histórico de mobilização, organização e ações coletivas anteriores ao surgimento das propostas de TBC.

Com relação à Interculturalidade, embora se reconheça que a conformação das iniciativas de TBC ofereça um ambiente singular e propício para a interação e a troca entre a população local e o turista, acredita-se que esse elemento deva ser analisado a partir de uma perspectiva não determinista, deixando, assim, de representar um aspecto constituinte do turismo comunitário.

Não conferir à interculturalidade um status de elemento-chave parte do entendimento que a demanda que consome esse produto não deve se reduzir ao movimento do turismo responsável. Ponta Grossa, por exemplo, entre as três iniciativas estudadas, é o local que recebe o maior fluxo de turistas, se beneficiando diretamente da demanda de Canoa Quebrada - um destino turístico consolidado e com projeção internacional. Mitchell e Muckosy (2008) ressaltam a importância de ligar comunidades "pobres" aos grandes fluxos turísticos, citando como exemplo a Ilha Taquile, no Lago Titicaca, que inseriu comunidades locais em uma das mais importantes rotas de turismo da região, capturando, assim, uma pequena parcela do

\footnotetext{
8 Segundo Bromley (1993, p.15), “rights are not relationships between me and an object, but are rather relationships between me and other with respect to that object. Rights can only exist when there is a social mechanism that gives duties and binds individuals to those rights."
} 
turista convencional. Tais realidades demonstram que uma iniciativa de TBC não precisa estar voltada apenas para o movimento do turismo responsável, podendo também se beneficiar de uma inserção diferenciada no mercado convencional.

A Qualidade Ambiental assume relevância nos territórios onde se desenrolam as práticas de TBC. Grande parte dessas iniciativas tem relação direta com áreas protegidas, o que reforça o vínculo entre o turismo comunitário e a conservação ambiental. No entanto, embora se reconheça uma preocupação ambiental entre os grupos envolvidos com o TBC, as observações no terreno mostram que nem sempre esta se traduz em práticas focadas na conservação do ambiente natural local. O percurso para se alcançar a qualidade ambiental está condicionado a uma série de variáveis (apoio externo, recursos financeiros e presença do Estado) que não estão sob o controle dos grupos comunitários. Em decorrência dessa complexidade, defende-se que essa dimensão não deve assumir o status de elemento constituinte, e sim ser interpretada como uma intenção das práticas de TBC.

O elemento Democratização de Oportunidades e Repartição de Benefícios baseou-se na perspectiva de alguns autores apresentarem o turismo comunitário como uma proposta associada à distribuição equitativa de renda na comunidade; vinculada à economia solidária; comprometida com a gestão coletiva, e pautada em práticas democráticas e solidárias. As iniciativas analisadas, entretanto, não apresentaram qualquer experiência inovadora com relação à propriedade, gestão e repartição de benefícios que se contraponham ao mercado convencional. Os resultados dos fundos de reserva e rotativo geridos pelas Associações locais são tímidos e passíveis de questionamentos. De um lado, constata-se uma fragilidade institucional e de gestão nas Associações; de outro, uma dificuldade dos proprietários e prestadores de serviços honrarem os acordos e compromissos assumidos com as suas respectivas organizações, em função do retorno financeiro limitado de seus negócios.

Acredita-se que trabalhar a temática do TBC a partir de uma perspectiva de contraposição ao mercado convencional é limitante. Estes dois pontos (democratização e repartição) devem ser analisados e reconhecidos como desdobramentos da dominialidade (criação de uma reserva de mercado e a estruturação de uma cadeia produtiva do turismo), que poderão ser potencializados pela atuação da organização local ("agência reguladora"). Defende-se, assim, um redirecionamento da abordagem teórica desse elemento, menos apoiada em ideologias "não mercantis", e mais focada na garantia da dominialidade e do fortalecimento das instituições locais.

A Integração Econômica também foi percebida como uma consequência direta dos efeitos da dominialidade, que pode ser fortalecida por meio da atuação da organização local (que deverá incentivar, promover e fortalecer essa integração). Nota-se que os empreendimentos turísticos estudados privilegiam, por princípio e por facilidade de logística, o consumo dos produtos locais, buscando externamente apenas aquilo que não se encontra na comunidade.

Logo, dos seis elementos-chaves propostos inicialmente, conclui-se, ao se confrontar teoria e prática, que apenas dois sejam realmente constitutivos do TBC: "Dominialidade" e "Organização Comunitária". Sugere-se que dois deixem de representar elementos-chaves e passem a receber outro status: "Interculturalidade" apresenta-se como uma possibilidade e "Qualidade Ambiental" como uma intenção. E, por fim, "Democratização de Oportunidades e Repartição de Benefícios" e "Integração Econômica" também deixam de configurar aspectos constituintes e passam a representar desdobramentos, efeitos e intenções dos elementos-chaves da "Dominialidade" e da "Organização Comunitária". 
A partir das evidências empíricas levantadas, observa-se que o arcabouço teórico do TBC tende a descrever um cenário adjetivado e idealizado, dificilmente condizente com as realidades encontradas. A resistência em tratar questões vinculadas à economia, ao mercado e à lucratividade dentro do TBC pode ser explicada por suas origens ideológicas, mas representa um aspecto que precisa ser debatido quando se trata da comercialização de produtos e serviços inerentes ao turismo.

Ressalta-se, por fim, que o volume das publicações acadêmicas brasileiras, além de limitado, tende a não consolidar dados que permitam aferir o desempenho do TBC - quanto ao fluxo turístico, taxa de ocupação dos meios de hospedagem, processos de gestão e, principalmente, como a atividade turística de base comunitária tem de fato contribuído para a melhoria das condições de vida dessas comunidades. Debruçar esforços de pesquisas sobre esses aspectos é importante, uma vez que trabalhos internacionais (MITCHELL; MUCKOSY, 2008; SIMPSON, 2008) apontam que a dificuldade de acesso ao mercado e a má governança têm levado essas iniciativas ao colapso financeiro.

\section{Referências}

ALMEIDA, H. L. P. S. de. Indicadores de Qualidade de Vida, instrumento para o monitoramento participativo da qualidade de vida de comunidades costeiras tradicionais: o caso Prainha do Canto Verde, Beberibe/CE. 2002. Dissertação (Mestrado em Desenvolvimento e Meio Ambiente) Universidade Federal do Ceará, Fortaleza.

ALMEIDA, H. L. P. S; PINHEIRO, J. C. V. A arte da sustentabilidade da pesca na comunidade da Prainha do Canto Verde, Beberibe/CE. XLII Congresso da Sober. Cuiabá-MS. 2004. Disponivel em: 〈http:// www.sober.org.br/palestra/12/05P306.pdf>. Acesso em: 26 jan. 2013.

AREF et al. Tourism Development in Local Communities: as a Community Development Approach. Journal of American Science. 6(2). p. 155-161, 2010.

BENEVIDES, I. P. Para uma agenda de discussão do turismo como fator de desenvolvimento local. In: RODRIGUES, A. B. (Org.). Turismo e Desenvolvimento Local. 3. ed. São Paulo: Hucitec, 1997. p. 23-41.

BLACKSTOCK, K. A critical look at community based tourism. Community Development Journal, v. 40, n. 01, p. 39-49, 2005.

BRASIL. Ministério do Turismo. Dinâmica e Diversidade do Turismo de Base Comunitária: desafio para a formulação de política pública. Brasília: Ministério do Turismo, 2010.

BROMLEY, D. W. Environment and Economy: Property Rights e Public Policy. Cambridge: Blackwell, 1993.

BURSZTYN, I. et al. Benchmarking: Prainha do Canto Verde. Caderno Virtual de Turismo, v. 3, n. 3, p. 18-32, 2003.

CORIOLANO, L. N. M. T. O Desenvolvimento voltado às condições humanas e o turismo comunitário. In: CORIOLANO, L. N. M. T; LIMA, L. C. (Org.). Turismo Comunitário e Responsabilidade Socioambiental. Fortaleza: Eduece, 2003. p. 26-44.

. 0 turismo comunitário no nordeste brasileiro. In: BARTHOLO, R.; SANSOLO, D. G; BURSZTYN, I. (Org.). Turismo de base comunitária: diversidade de olhares e experiências brasileiras. Rio de Janeiro: Letra e Imagem, 2009. p. 277-287. 
COSTA, H. A. Destinos do turismo: percursos para a sustentabilidade. Rio de Janeiro: FGV, 2013.

DIEGUES, A. C. 0 mito da Natureza Intocada. 4. ed. São Paulo: Hucitec, 2004.

IRVING, M. A. Reinventando a reflexão sobre turismo de base comunitária - inovar é possível? In: BARTHOLO, R.; SANSOLO, D. G.; BURSZTYN, I. (Org.). Turismo de base comunitária: diversidade de olhares e experiências brasileiras. Rio de Janeiro: Letra e Imagem, 2009. p. 108-119.

LIMA, M. C. Comunidades Pesqueiras Marítimas no Ceará: território, costumes e conflitos. 2002. Tese (Doutorado em Geografia Humana) - Departamento de Geografia da Faculdade de Filosofia, Letras e Ciências Humanas. Universidade de São Paulo, São Paulo.

LTDS. Laboratório de Tecnologia e Desenvolvimento Social. Relatório Técnico: Marco Referencial Teórico para o Turismo de Base Comunitária. Rio de Janeiro: PEP/COPPE/ UFRJ, 2011.

MALDONADO, C. O turismo rural comunitário na América Latina: gênesis, características e políticas. In: BARTHOLO, R.; SANSOLO, D. G.; BURSZTYN, I. (Org.). Turismo de base comunitária: diversidade de olhares e experiências brasileiras. Rio de Janeiro: Letra e Imagem, 2009. p. 25-44.

MENDONÇA, T. C. M. Turismo e participação comunitária: "Prainha do Canto Verde, a 'Canoa' que não quebrou e a 'Fonte' que não secou?”. 2004. Dissertação (EICOS - Programa de Estudos Interdisciplinares de Comunidades e Ecologia Social). Universidade Federal do Rio de Janeiro, Rio de Janeiro.

MITCHELL, J.; MUCKOSY, P. A misguided quest: community-based tourism in Latin America. Overseas Development Institute. 2008, p. 102-103.

SAMPAIO, C. A. et al. Perspectiva do turismo comunitário, solidário e sustentável. In: SAMPAIO, C. A. C.; HENRIQUEZ, C.; MANSUR, C. (Org.). Turismo comunitário, solidário e sustentável: da crítica às ideias e das ideias à prática. Blumenau: Edifurb, 2011. p. 23-30.

SANSOLO, D.; BURSZTYN, I. Turismo de base comunitária: potencialidade no espaço rural brasileiro. In: BARTHOLO, R.; SANSOLO, D. G.; BURSZTYN, I. (Org.). Turismo de base comunitária: diversidade de olhares e experiências brasileiras. Rio de Janeiro: Letra e Imagem, 2009. p. 142-161.

SIMPSON, M. C. Community benefit tourism initiatives - A conceptual oxymoron? Tourism Management, v.29, p.1-18, 2008.

SINGER, P. Introdução à Economia Solidária. São Paulo: Fundação Perseu Abramo, 2010. 